\title{
Pierre Robin sequence: Subdivision, data, theories, and treatment - Part 3: Prevailing controversial theories related to Pierre Robin sequence
}

\begin{tabular}{|l|}
\hline Access this article online \\
\hline Website: \\
www.amsjournal.com \\
\hline DOI: \\
10.4103/2231-0746.186135 \\
\hline Quick Response Code: \\
\hline
\end{tabular}

\author{
Kurt-W Bütow ${ }^{1,2,3}$, Roger Arthur Zwahlen ${ }^{4}$, Jean A. Morkel ${ }^{5}$, Sharan Naidoo ${ }^{1}$ \\ ${ }^{1}$ Department of Maxillo-Facial and Oral Surgery, Facial Cleft Deformity Clinic, University of Pretoria, \\ ${ }^{2}$ Suite A2-Maxillofacial Surgery, The Wilgers Hospital, Pretoria, ${ }^{3}$ Department of Maxillofacial Surgery, \\ Division of Dentistry, College of Health Sciences, University of KwaZulu-Natal, Durban, ${ }^{5}$ Department of \\ Maxillo-Facial and Oral Surgery, University of the Western Cape, Cape Town, South Africa, ${ }^{4}$ Discipline of \\ Oral and Maxillofacial Surgery, University of Hong Kong, Hong Kong S. A. R., PR China
}

Address for correspondence: Prof. Roger Arthur Zwahlen, Oral and Maxillofacial Surgery, Faculty of Dentistry, The University of Hong Kong, 34 Hospital Road, Hong Kong SAR, PR China.

E-mail: zwahlen@hku.hk

\section{ABSTRACT}

Context: The disorder currently accepted as Pierre Robin syndrome/anomaly/sequence (PRS) has been plagued by controversy ever since initially being described. Controversy exists not only about the appropriate terminology and etiopathogenesis of the disorder but also about its management. Therefore, clinical findings and treatment outcomes of a large database of 266 PRS cases were compared with the current state of knowledge in the scientific literature related to history, clinical description, diagnostic criteria, epidemiology, theories of oligohydramnios, mandibular catch-up growth, midfacial hyperplasia, and the early management. Aim: The aims of Part 3 debate the controversial biological theories relating to PRS. Materials and Methods: Oligo-/poly-hydramnios, mandibular catch-up growth, and midfacial hyperplasia, the three in the literature most prevailing theories related to PRS, have been compared and discussed with the findings provided by this large database of 266 Siebold-Robin sequence (SRS) and Fairbairn-Robin triad (FRT) cases.

Results: History and clinical findings evaluated in this database refute the first two theories. Although manifold midfacial appearances were demonstrated in FRT cases, a third of all SRS cases presented with mid-facial hyperplasia.

Conclusion: The three main biological theories regarding PRS could not be verified after thorough analysis of the database.

Keywords: Catch-up growth, Fairbairn-Robin triad, maxillary hypoplasia, micrognathia, oligohydramnios, Pierre Robin sequence, polyhydramnios

\section{INTRODUCTION}

Various broadly accepted theories of origin exist about facial growth disturbances in patients suffering from Pierre Robin sequence (PRS).

In 1923, Robin initially reported the association between retrognathia/micrognathia and glossoptosis. ${ }^{[1]}$ In the course of time, a theory originated that the observed under-development of the mandible and its adjacent anatomical structures occur due to gestational oligohydramnios or polyhydramnios. In 1985, Edwards and Newall[2] concluded that a purely mechanistic etiopathogenesis such as the oligohydramnios theory could not be supported when reviewing the subject-specific scientific

This is an open access article distributed under the terms of the Creative Commons Attribution-NonCommercial-ShareAlike 3.0 License, which allows others to remix, tweak, and build upon the work non-commercially, as long as the author is credited and the new creations are licensed under the identical terms.

For reprints contact: reprints@medknow.com

Cite this article as: Bütow KW, Zwahlen RA, Morkel JA, Naidoo S. Pierre Robin sequence: Subdivision, data, theories, and treatment - Part 3: Prevailing controversial theories related to Pierre Robin sequence. Ann Maxillofac Surg 2016;6:38-43.

(C) 2016 Annals of Maxillofacial Surgery | Published by Wolters Kluwer - Medknow 
literature. They hypothesised that more likely, the combination of a metabolic disorder, together with a secondary intrauterine mechanical obstruction or restriction of mandibular growth, causes the mandibular growth disorder. They, therefore, suggested abolishing the term anomalad and introducing the term maxillomandibular dysgenesis or syndrome instead. Furthermore, they considered making the diagnosis irrespective of the degree of mandibular micrognathia, especially because PRS could result in the first line due to a metabolic disorder which prevented the elevation and fusion of the palatal shelves. ${ }^{[2]}$ Consecutively, an assumption arose that the mandibular growth disturbance, due to intrauterine mechanical restriction or neurophysiological factors, ${ }^{[3]}$ might be compensated for by postpartum "catch-up" growth. The observation that without apparent reason, both hypoplastic midfacial structures and/or mandible occur in this type of facial malformation, led to the hypothesis of an underlying inherited bimaxillary growth disorder based on organogenetic factors. ${ }^{[4]}$

In Part 3 of this publication, three broadly accepted biological theories related to facial growth disturbances in patients with PRS have been compared with the clinical findings from a database of 266 Siebold-Robin sequence (SRS) and Fairbairn-Robin triad (FRT) cases.

\section{MATERIALS AND METHODS}

The 266 PRS cases analyzed in this research were divided into two groups, namely,

- SRS clinically diagnosed as micro- or retro-gnathia with glossoptosis, with or without airway obstruction

- FRT with the clinical features of SRS as well as a cleft palate.

Three prominent theories related to accompanying facial growth disturbances in patients suffering from PRS have been compared to the clinical findings in this presented database:

- Gestational oligo- or poly-hydramnios leading to intrauterine restriction of embryonic/fetal movement with consecutive mandibular growth disturbance

- Postnatal mandibular catch-up growth resulting to a large extent in recovery of mandibular-related facial deformities

- Both midfacial hypo- and hyper-plasia being assumed to occur due to midfacial growth disturbances.

\section{RESULTS}

Of the total of 266 cases reviewed, only 169 (63.5\%) PRS patients and their mothers attended a follow-up appointment where information about pregnancy history, catch-up growth, and midfacial appearance could be gathered [Tables 1-3]. The remaining patients could not be followed up with due to unknown addresses or reasons such as age, indisposition, and/ or disinterest.

Where available, information was obtained from the obstetrics notes of a patient's mother regarding prenatal oligo- or poly-hydramnios and where these two conditions were reviewed and evaluated with the mother.

Catch-up growth was not evaluated in infants younger than 24 months.
Midfacial appearance was documented under the headline of clinical appearances and verified by a second craniomaxillofacial surgeon.

Cephalometric analysis was performed in children of 14 years and older.

\section{Oligohydramnios and polyhydramnios}

Table 1 highlights the comparison of the records of SRS and FRT patients regarding gestational oligo- and poly-hydramnios.

A pregnancy history could be retrieved in 169 (63.5\%) of the 266 patients. Whereas oligohydramnios was noted in $20.5 \%$ (32 of 156) among patients with FRT and $61.5 \%$ (8 of 13) with SRS and polyhydramnios was registered in $6.4 \%$ (10 of 156) patients with FRT and $7.7 \%$ (1 of 13 ) with SRS [Figure 1]. ${ }^{[5]}$

\section{Occurrence of catch-up growth}

Table 2 highlights the detailed analysis of syndromic and nonsyndromic SRS and FRT cases, oligo- or poly-hydramnios and positive family history with mandibular catch-up and noncatch-up growth.

Mandibular catch-up [Figure 2a and b] and noncatch-up growth [Figure 3a and b] were evaluated in 59.8\% (159 of 266) of the patients in this database. Whereas none

Table 1: Oligohydramnios and polyhydramnios

\begin{tabular}{|c|c|c|c|c|}
\hline \multirow[t]{2}{*}{ Total 266 (PRS) } & \multicolumn{2}{|c|}{ Oligohydramnios } & \multicolumn{2}{|c|}{ Polyhydramnios } \\
\hline & SRS & FRT & SRS & FRT \\
\hline 169 (verified pregnancy history) & \multicolumn{2}{|c|}{40} & \multicolumn{2}{|c|}{11} \\
\hline Oligohydramnios & 8 & 32 & & \\
\hline Polyhydramnios & & & 1 & 10 \\
\hline
\end{tabular}

Table 2: Catch-up growth

\begin{tabular}{lcc}
\hline Total (266 PRS) & $\begin{array}{c}\text { Catch-up } \\
\text { growth }\end{array}$ & $\begin{array}{c}\text { Non-catch-up } \\
\text { growth }\end{array}$ \\
\hline 159 (verified mandibular catch-up growth) & & \\
SRS & 0 & 13 \\
FRT & 51 & 95 \\
Non-syndromic (FRT) & 42 & 89 \\
Syndromic (FRT) & 9 & 19 \\
Oligo- or polyhydramnios (FRT) & 9 & 23 \\
Positive family history (FRT) & 14 & 25 \\
\hline
\end{tabular}

PRS=Pierre Robin sequence; SRS=Siebold-Robin sequence; FRT=Fairbairn-Robin triad

\section{Table 3: Midfacial appearances}

\begin{tabular}{lccc}
\hline Total (266 PRS) & Normal & Hyperplasia & Hypoplasia \\
\hline 174 (midfacial evaluation) & & & \\
PRS & 126 & 41 & 7 \\
SRS & 11 & 6 & 0 \\
FRT & 115 & 35 & 7 \\
\hline
\end{tabular}

PRS=Pierre Robin sequence; SRS=Siebold-Robin sequence; FRT=Fairbairn-Robin triad 


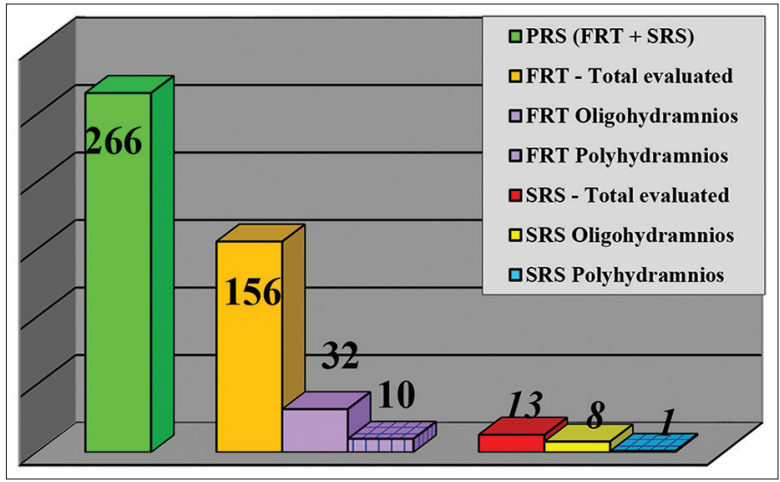

Figure 1: Oligohydramnios and polyhydramnios

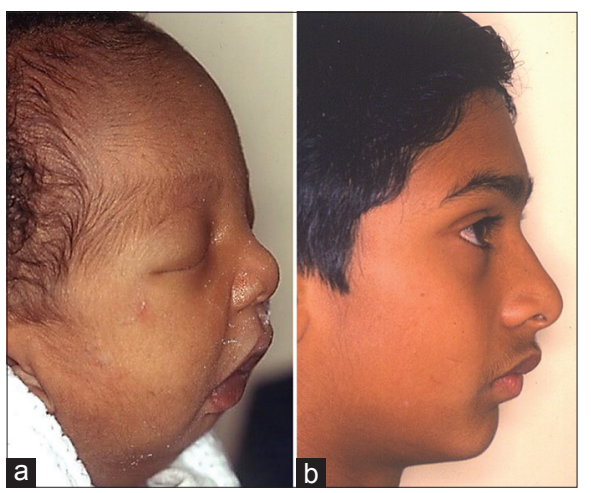

Figure 3: ( $a$ and b) Mandibular noncatch-up growth in Fairbairn-Robin triad

of the 13 evaluated SRS cases revealed catch-up growth, $34.9 \%$ (51 of 146) of FRT patients presented with catch-up growth [Figure 4], ${ }^{[5]} 82.4 \%$ (42 of 51 ) of which were nonsyndromic cases.

It has been discovered that in $17.6 \%$ (9 out of 51 ) of FRT patients showing mandibular catch-up growth, the mother suffered from oligo- or poly-hydramnios during pregnancy. Furthermore, it has been noted that $27.5 \%$ (14 of 51) of FRT patients revealed a cleft lip palate positive family history.

\section{Midfacial appearances}

Table 3 provides a survey of the midfacial appearances of 174 SRS and FRT patients.

Midfacial appearances were evaluated in $65.4 \%$ of this database. Of the 17 SRS patients, $6(35.3 \%)$ presented with midfacial hyperplasia and none with hypoplasia. Among the FRT patients, $22.3 \%$ (35 of 157) displayed a midfacial hyperplasia and only seven $(4.5 \%)$ presented with hypoplasia [Figure 5]. All seven cases with midfacial hypoplasia had a Binderoid appearance [Figures 6 and 7]. Two of these were siblings with a genetically proven Stickler syndrome.

\section{DISCUSSION}

It has been stated that too little (= oligohydramnios) as well as too much (= polyhydramnios) amniotic fluid might lead to postnatal compromised airways with associated malformations as found in SRS/FRT. ${ }^{[6]}$ One of the most widespread theories

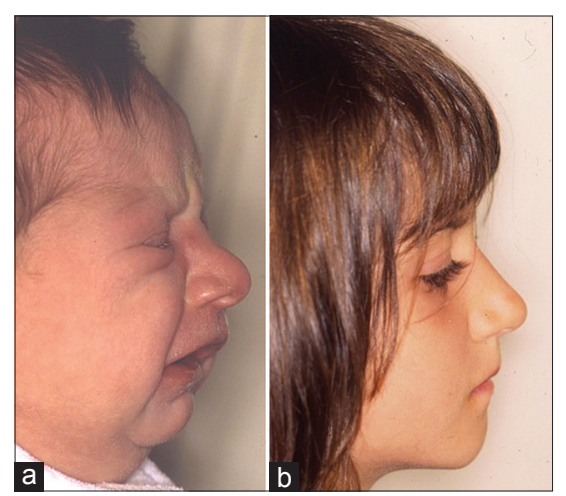

Figure 2: $(a$ and b) Mandibular catch-up growth in Fairbairn-Robin triad

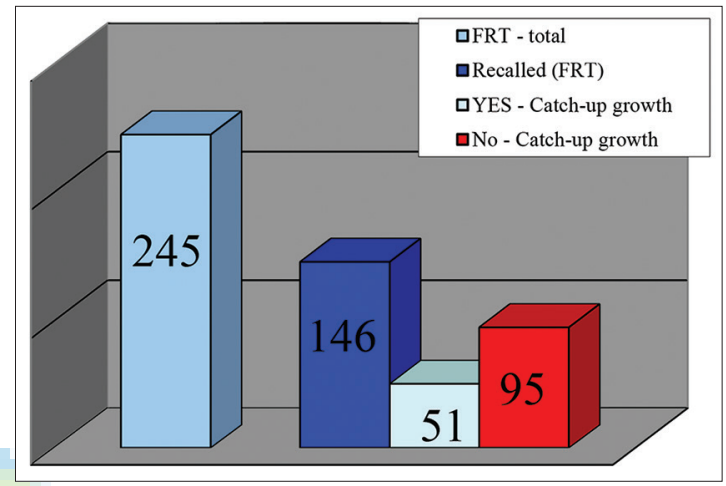

Figure 4: Catch-up growth in Fairbairn-Robin triad

related to the origin of SRS/FRT in new-borns involves the existence of oligohydramnios during the mother's pregnancy. Oligohydramnios is believed to cause limitation of the normal extension range of the flexed fetal head. This limitation in turn presents a hindrance to mandibular growth due to mechanical compression of the mandible onto the sternum. It is deemed that this restricted mandibular growth inhibits the downward and forward movement of the tongue, thereby impeding the elevation and fusion of the palatal shelves. ${ }^{[7,8]}$ This restricted growth was the motivation behind the change in terminology from Pierre Robin syndrome to anomalad as the latter is defined as a malformation with subsequent structural changes. ${ }^{[9,10]}$

In addition, downward and forward movement of the tongue becomes restricted, thereby resulting in microglossia secondary to compromised mandibular growth. This further impedes the elevation and fusion of the palatal shelves, ${ }^{[7,8]}$ resulting in a cleft palate malformation (FRT). Experiments on rats ${ }^{[7,8]}$ provided scientific support to back up the theory of mandibular catch-up growth.

Contrary to the popular origin theory that oligohydramnios is the major contributing factor, certain publications dealing with prenatal SRS/FRT diagnosis consider polyhydramnios to also be a risk factor for PRS. ${ }^{[10,11]}$ Polyhydramnios is presumed to be the result of intrauterine decreased fetal swallowing, which in turn causes a retro- or even micro-gnathia with a consecutive cleft palate malformation.

Sonographic findings of oligo- or poly-hydramnios should thus be carefully recorded and detection should alert clinicians 


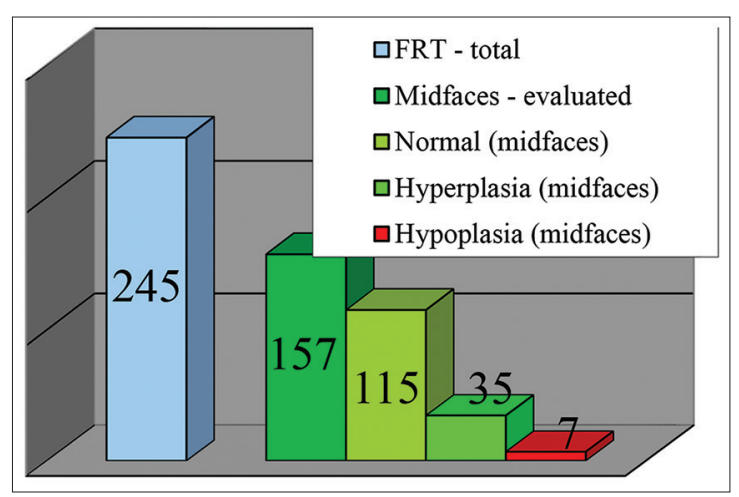

Figure 5: Midfacial appearances in Fairbairn-Robin triad

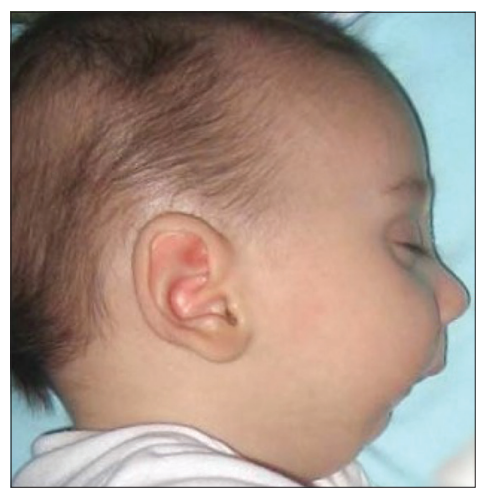

Figure 6: Normal midfacial appearance of a Fairbairn-Robin triad

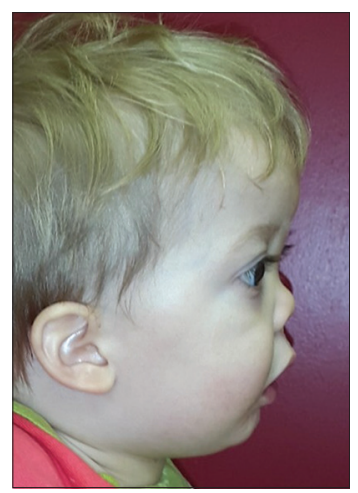

Figure 7: A binderoid midfacial appearance of a Fairbairn-Robin triad

to the possibility of developing SRS/FRT or other common characteristics of these entities, such as micro- or retro-gnathia with or without microglossia and cleft palate malformations. ${ }^{[12]}$ If aforementioned conditions are present during a sonographic scan, it is recommended that the heart be screened as well, especially as cardiac abnormalities are reported in $20 \%$ of patients diagnosed with micrognathia. ${ }^{[6,13]}$ Whereas $3.4 \%$ of all patients evaluated in this database presented with a cardiac abnormality, only one SRS patient, whose mother reported polyhydramnios during pregnancy, suffered from a congenital heart defect. This rather low percentage sharply contrasts a 50\% occurrence of congenital heart defects in FRT patients with a prenatal history of oligohydramnios. Karyotyping of the fetus has been recommended as chromosomal abnormalities have been discovered in $45 \%$ of a patient sample where micrognathia had been diagnosed sonographically. ${ }^{[6]}$ In this database, chromosomal/genetic abnormalities have been confirmed in only $13.5 \%$ of all cases.

In the database under discussion, $63.5 \%$ of the records provided information relating to maternal oligo- and poly-hydramnios during pregnancy. Whereas mothers with oligohydramnios were recorded in $20.5 \%$ of FRT and $61.5 \%$ of SRS patients, those with polyhydramnios prevailed in only $6.4 \%$ of FRT and $7.7 \%$ of SRS patients.

The oligohydramnios/polyhydramnios theory as an origin of PRS is broadly acknowledged within the professional community. However, the overall incidence of $30.2 \%$, i.e. $23.7 \%$ for oligohydramnios and $6.5 \%$ for polyhydramnios presented in this database [Table 1], suggests that it should be kept in perspective. That said, oligohydramnios is nevertheless strongly represented in the SRS division with $61.5 \%$ whereas it is relatively low with only $20.5 \%$ in the FRT division. Therefore, it seems that the oligohydramnios and polyhydramnios theories might be considered to be strongly causative for intrauterine mandibular growth disorder in patients with SRS while they might be deemed to be of less importance in FRT patients.

The mandibular catch-up growth theory is highly controversial. A number of cephalometric studies have not been able to substantiate catch-up growth. ${ }^{[14,15]}$ As multiple structural middle and inner ear defects were found in one postmortem case, ${ }^{[16]}$ partial abnormalities of Meckel's cartilage might be considered to be involved in the pathogenesis of SRS/FRT ${ }^{[17]}$ Conversely, this argues for a postnatal mandibular noncatch-up growth. Many authors ${ }^{[11,17]}$ however, commented on the notion of mandibular catch-up growth. This is believed to occur postnatal due to an inherent normal mandibular growth potential as soon as the intrauterine mechanical growth restriction due to oligohydramnios ends.

Syndromic patients are considered to have a primary mandibular growth disorder and therefore do not show any postnatal potential for catch-up growth. ${ }^{[18,19]}$ When comparing 2 -year-old children suffering from nonsyndromic SRS/FRT and isolated cleft palate (ICP) with unimpaired children, a significantly faster increase of mandibular length was detected in children with SRS/FRT. ${ }^{[15]}$

However, another study comparing toddlers suffering from SRS/FRT with unimpaired children during their $1^{\text {st }}$ year of life did not discover any mandibular growth difference between the two groups. ${ }^{[16]}$ In 2001, Daskalogiannakis et al. ${ }^{[17]}$ noted no catch-up growth in patients with SRS/FRT or in patients with ICP after the age of 5 years. This finding was later confirmed by others matching the mandibular growth between ICP patients and patients with nonsyndromic SRS/FRT up to the age of 22 months. ${ }^{[18]}$

Thus far, the evidence indicates that depending on the etiology of intrauterine growth restriction due to oligo- or poly-hydramnios, mandibular catch-up growth does occur, but not sufficiently to produce a postnatal normal facial profile with a normal jaw. ${ }^{[17]}$

As represented in Table 2, mandibular catch-up growth was observed in the represented database in $34.9 \%$ of FRT patients of whom $82.4 \%$ were nonsyndromic. In the noncatch-up growth group, $82.1 \%$ were nonsyndromic FRT patients and $84.6 \%$ 
were nonsyndromic SRS patients. These results seem to confirm that slightly more than one-third of the patients with FRT might experience mandibular catch-up growth, the majority of them being nonsyndromic.

Furthermore, $27.5 \%$ in the FRT catch-up growth group had a family history of cleft lip and/or palate. However, a prenatal history of oligo- or poly-hydramnios was revealed in only $17.4 \%$ of FRT patients with mandibular catch-up growth. These database results challenge both theories: Oligohydramnios with intrauterine mechanical mandibular growth restriction, as well as the theory that postnatal mandibular catch-up growth occurs once the intrauterine compromise to the mandibular growth pattern has subsided.

Existing midfacial hypoplasia in patients with SRS/FRT is interesting, especially in light of the view that the mandible is micro- or retro-gnathic, thereby accentuating the facial deformity in the anteroposterior dimension. An evaluation by means of computerized morphometric facial analysis in SRS/FRT infants found substantial midfacial hypoplasia, together with,

- A virtually normal anterior maxillary vertical development

- A significantly reduced posterior height of the maxilla. ${ }^{[20]}$

In 2001, Daskalogiannakis et al. ${ }^{[17]}$ supported the lack of maxillary growth in a cephalometric analysis. In their study, they compared maxillary growth of postoperative PRS with that of ICP patients and noted that the anteroposterior midfacial dimension in PRS patients was significantly shorter. However, it remains unclear whether the investigated cases represent cases with true midfacial hypoplasia, or whether they show a compensatory midfacial hyperplasia due to a relatively less pronounced mandibular micrognathia. In PRS, the micro-/retro-gnathia appears more severe due to a midfacial "hyperplasia" because platybasia (cranial base angle $\geq 137^{\circ}$ ) as found, or is this only a relative appearance due to the platybasia? ${ }^{[21]}$ These findings are analogous to those of Amaratunga ${ }^{[22]}$ who had followed-up patients with midfacial hypoplasia for a minimum of 2 years. Similar findings were confirmed in a more recent three-dimensional assessment. ${ }^{[23]}$

Results from the analysis of the study database exhibit various types of midfacial appearances for patients with SRS and FRT. In SRS group, midfacial hyperplasia occurred in $35.3 \%$ of the study patients without any cases of hypoplasia. On the contrary, patients with FRT revealed manifold midfacial appearances such as those documented in Table 3:

- Midfacial hypoplasia: $4.5 \%$

- Hyperplasia: $22.3 \%$

- Normal midfacial appearance: $73.2 \%$.

These findings are contrary to those previously published. ${ }^{[17,19,22,23]}$

A wide $U$-shaped hard and soft palate cleft is usually found in FRT patients. It is worth considering whether midfacial hypoplasia in FRT patients can be considered to be a sequel of extensive palatal surgery. It would be particularly significant to establish whether it is due to specific reconstructive procedure (s) and/or the timing of primary cleft surgery and/or possible additional velopharyngeal surgery. Important questions to consider here are the following:

- Could future facial dysgnathic growth patterns be the result of surgical procedures, especially those involving extensive palatal mucoperiosteal stripping, as well as the time lapse between birth and the surgical intervention (s)?

- Would the mandible still show relative catch-up growth in such cases with midfacial growth restriction when examining them as adolescents in cephalometric analysis?

On the other hand, a hyperplastic midface in neonates, as found in $23.6 \%$ of this database, exacerbates the appearance of a mandibular hypoplasia. During growth, such children and future adolescents may present with a much more normal relationship in the anteroposterior dimension of the face due to previous cleft surgery, with or without velopharyngeal reconstruction or due to a platybasic skull base.

In the field of PRS research, this disorder is generally accepted as an inhomogeneous facial malformation consisting of two main groups, the SRS and FRT with possible additional subdivisions, each presenting with different facial growth patterns. This study compared various craniomaxillofacial tenets, related to facial growth disturbances in patients with PRS with clinical findings from a database of 266 SRS and FRT cases. Findings in scientific literature related to oligo- and poly-hydramnios, mandibular catch-up growth, and midfacial hypo- and hyper-plasia tenets in PRS patients could only partially be supported. Although gray areas still exist, these clinical findings might widen the scope of discussion, thus providing a platform for future research.

\section{CONCLUSION}

The three main biological theories regarding PRS could not be verified after thorough analysis of the database.

\section{Declaration of patient consent}

The authors certify that they have obtained all appropriate patient consent forms. In the form the patient(s) has/have given his/her/their consent for his/her/their images and other clinical information to be reported in the journal. The patients understand that their names and initials will not be published and due efforts will be made to conceal their identity, but anonymity cannot be guaranteed.

\section{Acknowledgement}

The authors would like to thank Mrs Jennilee Blom for her invaluable job as research assistant.

\section{Financial support and sponsorship}

Nil.

\section{Conflicts of interest}

There are no conflicts of interest.

\section{REFERENCES}

1. Robin P. La glossoptose. Son diagnostic, ses conséquences, son traitement. [A fall of the base of the tongue considered as new cause of nasopharyngeal respiratory impairment]. Bull Acad Natl Med 1923;89:37-41.

2. Edwards JR, Newall DR. The Pierre Robin syndrome reassessed in the light of recent research. Br J Plast Surg 1985;38:339-42.

3. Abadie V, Morisseau-Durand MP, Beyler C, Manach Y, Couly G. Brainstem dysfunction: A possible neuroembryological pathogenesis 
of isolated Pierre Robin sequence. Eur J Pediatr 2002;161:275-80.

4. Rintala A, Ranta R, Stegars T. On the pathogenesis of cleft palate in the Pierre Robin syndrome. Scand J Plast Reconstr Surg 1984;18:237-40.

5. Bütow KW, Zwahlen RA. Pierre Robin sequence treatment. In: Bütow KW, Zwahlen RA, editors. Cleft - Ultimate Treatment. $2^{\text {nd }}$ ed. Durban: Reach Publisher; 2016. p. 337-65.

6. Figueroa AA, Glupker TJ, Fitz MG, BeGole EA. Mandible, tongue, and airway in Pierre Robin sequence: A longitudinal cephalometric study. Cleft Palate Craniofac J 1991;28:425-34

7. Hsieh YY, Chang CC, Tsai HD, Yang TC, Lee CC, Tsai CH. The prenatal diagnosis of Pierre-Robin sequence. Prenat Diagn 1999;19:567-9.

8. Malinger G, Rosen N, Achiron R, Zakut H. Pierre Robin sequence associated with amniotic band syndrome ultrasonographic diagnosis and pathogenesis. Prenat Diagn 1987;7:455-9.

9. Monroe CW, Ogo K. Treatment of micrognathia in the neonatal period. Report of 65 cases. Plast Reconstr Surg 1972;50:317-25.

10. Laitinen SH, Heliövaara A, Ranta RE. Craniofacial morphology in young adults with the Pierre Robin sequence and isolated cleft palate. Acta Odontol Scand 1997;55:223-8.

11. Vegter F, Hage JJ, Mulder JW. Pierre Robin syndrome: Mandibular growth during the first year of life. Ann Plast Surg 1999;42:154-7.

12. Chamberlain PF, Manning FA, Morrison I, Harman CR, Lange IR. Ultrasound evaluation of amniotic fluid volume. I. The relationship of marginal and decreased amniotic fluid volumes to perinatal outcome. Am J Obstet Gynecol 1984;150:245-9.

13. Igarashi M, Filippone MV, Alford BR. Temporal bone findings in Pierre Robin syndrome. Laryngoscope 1976;86:1679-87.

14. Diewert VM. Correlation between alterations in Meckel's cartilage and induction of cleft palate with beta-aminoproprionitrile in the rat Teratology 1981;24:43-52.

15. Gorlin RJ, Cohen MM, Levin LS. Robin sequence. In: Gorlin RJ, Cohen MM, Levin LS, editors. Syndromes of the Head and Neck. New York, Oxford: University Press; 1990. p. 860-5, 913-7.

16. Markovic M. Growth changes in cases of mandibular micrognatha. Trans Eur Orthod Soc 1972;48:133-45.

17. Daskalogiannakis J, Ross RB, Tompson BD. The mandibular catch-up growth controversy in Pierre Robin sequence. Am J Orthod Dentofacial Orthop 2001;120:280-5.

18. Eriksen J, Hermann NV, Darvann TA, Kreiborg S. Early postnatal development of the mandible in children with isolated cleft palate and children with nonsyndromic Robin sequence. Cleft Palate Craniofac J 2006;43:160-7.

19. Bacher M, Bacher U, Göz G, Pham T, Cornelius CP, Speer CP, et al. Three-dimensional computer morphometry of the maxilla and face in infants with Pierre Robin sequence - A comparative study. Cleft Palate Craniofac J 2000;37:292-302.

20. Walker BE. Effects on palate development of mechanical interference with the fetal environment. Science 1959;130:981.

21. Nachmani A, Aizenbud D, Berger G, Berger RL, Hazan-Molina H, Finkelstein $Y$. The prevalence of platybasia in patients with velopharyngeal incompetence. Cleft Palate Craniofac J 2013;50:528-34.

22. Amaratunga NA. A comparative clinical study of Pierre Robin syndrome and isolated cleft palate. Br J Oral Maxillofac Surg 1989;27:451-8.

23. Krimmel M, Kluba S, Breidt M, Bacher M, Dietz K, Buelthoff H, et al. Three-dimensional assessment of facial development in children with Pierre Robin sequence. J Craniofac Surg 2009;20:2055-60.

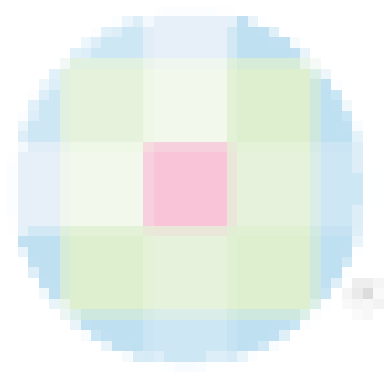

